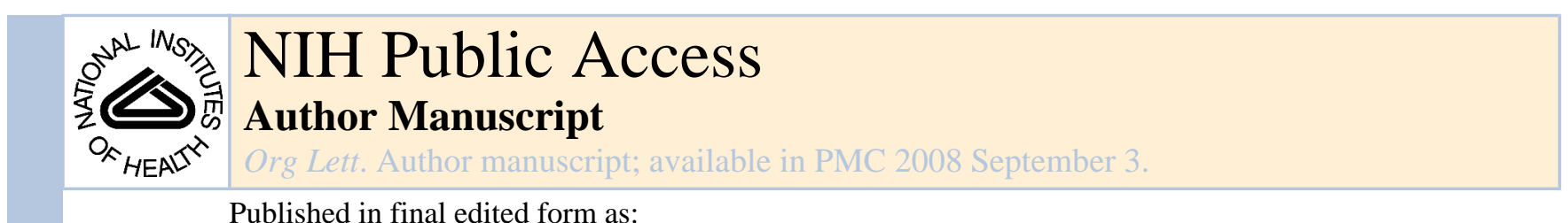

Published in final edited form as:

Org Lett. 2006 May 11; 8(10): 2023-2026. doi:10.1021/ol060414i.

\title{
A Fluorogenic Phospholipid Substrate to Detect Lysophospholipase D/Autotaxin Activity
}

\author{
Colin G. Ferguson ${ }^{\dagger}$, Cleve S. Bigman ${ }^{\dagger}$, Robyn D. Richardson ${ }^{\dagger}$, Laurens A. van Meeteren ${ }^{\ddagger}$ \\ Wouter H. Moolenaar $\ddagger$, and Glenn D. Prestwich $\S$ \\ Echelon Biosciences Inc., 675 Arapeen Drive 302, Salt Lake City Utah, 84108, The Netherlands \\ Cancer Institute, Plesmanlaan 121, 1066 CX Amsterdam, The Netherlands, Department of \\ Medicinal Chemistry, University of Utah, Salt Lake City, Utah, 84108
}

\begin{abstract}

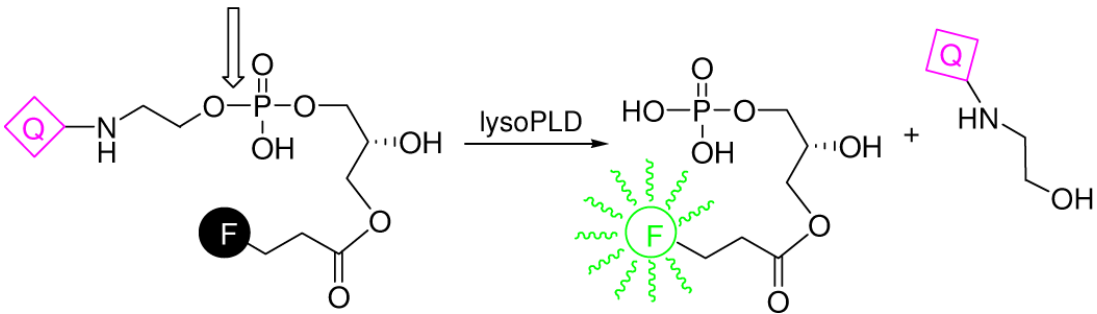

Lysophospholipase D (lysoPLD), also known as Autotaxin (ATX), is an important source of the potent mitogen lysophosphatidic acid (LPA). Two fluorogenic substrate analogs for lysoPLD were synthesized in nine steps from (S)-PMB-glycerol. The substrates (FS-2 and FS-3) show significant increases in fluorescence when treated with recombinant ATX and have potential applications in screening for this emerging drug target.
\end{abstract}

Bioactive lysophospholipids, such as lysophosphatidic acid (LPA, and sphingosine 1phosphate (S1P), exhibit pleiomorphic effects on multiple cell lineages, including ovarian cancer cells. ${ }^{1}$ LPA and S1P signal through specific cell surface receptors of the endothelial cell differentiation gene (formerly known as $e d g$ ) family of cell surface seven-transmembranedomain G-protein-coupled receptors. ${ }^{2}$ The purification, characterization, and identification of the ovarian cancer activating factor (OCAF) from ascites of ovarian cancer patients demonstrated that OCAF is comprised of numerous forms of LPA, and accounts for the ability of ascites to activate ovarian cancer cells. ${ }^{3}$ LPA, at concentrations present in ascites from ovarian cancer patients $(1-80 \mu \mathrm{M})$, increases proliferation under anchorage-dependent and independent conditions, prevents apoptosis and anoikis, increases invasiveness, induces cytoskeletal reorganization and change of shape, and decreases sensitivity to cisplatin. ${ }^{4}$

LPA can arise through at least two routes: the loss of the $s n-2$ acyl chain by phosphatidic acid specific PLA 2 or cleavage of the choline group of lysophosphatidylcholine (LPC) by lysophospholipase D (lysoPLD)(Figure 1A). LysoPLD activity was first characterized over

\footnotetext{
çferguson@echelon-inc.com.

tEchelon Biosciences Inc.

${ }_{\text {Netherlands Cancer Institute }}$

§University of Utah
}

Supporting Information Available Experimental procedures and characterizations for all new compounds. This material is available free of charge via the Internet at http://pubs.acs.org. 
sixteen years ago and has important roles in normal physiology as a source of plasma LPA. ${ }^{5}$ Two laboratories have independently determined purified and cloned plasma lysoPLD and showed that there was no sequence homology to other PLD enzymes. Instead, it was identical to secreted Autotaxin (ATX), a member of the nucleotide pyrophosphatase/phosphodiesterase (NPP) family of ecto/exo-enzymes, that stimulates tumor cell motility and has an in vivo role in tumor progression and invasion. 6

Recent reviews suggest that inhibition of increased lysoPLD/ATX activity by small molecules could be an attractive new avenue for anti-cancer chemotherapy, however for that to become reality, a simple assay for high throughput screening is needed. 7

A number of different methods have been employed to assay lysoPLD activity. ${ }^{8}$ Early work was performed with ${ }^{14} \mathrm{C}$-palmitoyl-LPC and radio-thin layer chromatography (TLC). This was supplanted by a TLC purification of unlabeled LPA with GC analysis of methyl esters, or by measurement of LPA-trimethylsilyl ether by gas chromatography-mass spectrometry (GC-

MS). An endpoint-type dual-enzymatic photometric assay has recently been employed to detect choline liberated from exogenously added LPC. ${ }^{6 \mathrm{c}}$ However, these methods are complex and are not suited to high throughput screening. During the course of this project the application of a doubly labeled ATX substrate, CPF4, was published. ${ }^{9}$ CPF4 is a fluorescence resonance energy transfer (FRET) substrate derived from bis- $p$-nitrophenylphosphate, a common colourimetric phosphodiesterase substrate, and while it was a significant improvement over the previously described assays, it does not share many structural features of the substrate. In this report, the synthesis and validation of two simple fluorogenic phospholipid substrates for lysoPLD/ATX activity are demonstrated.

The envisioned substrates employ a "fluorescence dequenching" motif, in which a fluorophore that is "silent" because of intramolecular FRET to a non-fluorescing quencher, becomes fluorescent once enzymatic hydrolysis cleaves the substrate (Figure 1B). This FRET paradigm has been applied to fluorogenic assays for ceramidase, ${ }^{10}$ DNA ligase, ${ }^{11} \mathrm{PLA}_{2}, 12$ and nucleic acid hybridization. ${ }^{13}$ Since, ATX is reported to hydrolyze variety of acyl chain modifications and is also tolerant to changes in the backbone and headgroup, ${ }^{14}$ a labeled ethanolamido head group was chosen for FS-2 and FS-3 (Figure 1C), rather than a synthetically more complex choline analog. In addition, a PEG tether was appended to the headgroup to move the bulkier fluor or quencher away from the phosphodiester and increase hydrophilicity. Dabcyl was chosen as the quencher for both substrates since it has been shown to effectively quench green fluors in the previously described applications. In FS-2, the hydrophobic fluor BODIPY@-FL is appended to the sn- 1 acyl chain with dabcyl on the head group. For FS-3, the positions of the quencher and fluor are reversed and BODIPY $®-F L$ was replaced with more hydrophilic fluorescein.

The synthesis of FS-2 and FS-3 is described in Scheme 1. A number of considerations were taken into account when designing the synthetic strategy. Since the majority of commercially available dyes are amine-reactive, orthogonally protected amino groups in the head group and monoacyl glycerol were required, in this case $\mathrm{Cbz}$ and Boc were chosen. In addition, a universal intermediate (9) was desired so that different combinations of fluors and quenchers could be potentially attached, thus allowing simple alteration of structual and/or fluorogenic properties. The PEG head group (2) was prepared by coupling commercially available Cbz-protected $\mathrm{PEG}_{4}$ acid (1) with ethanolamine by DCC/HOBt. To prepare the protected monoacyl glycerol segment, $p$-methoxybenzyl glyceryl ether 3 (prepared from $(S)$-isopropylideneglycerol ${ }^{15}$ ), was first selectively esterified at the primary hydroxyl with N-Boc-caproic acid forming 4 in $47 \%$ yield. ${ }^{16}$ Attempts to protect the $s n-2$ hydroxyl as the tert-butyl ether, which could be removed with the Boc group at the end of the synthesis, resulted in poor yields. Instead it was protected as the tert-butyldimethylsilyl ether (5) based on examples in the literature showing TBS ethers 
could be cleaved under acidic conditions. Oxidative cleavage of the PMB group gave the chiral intermediate 6. Phosphitylation of the hydroxyl with benzyl bisdiisopropylphosphoramidite yielded phosphoramidite 7 . The protected glycerol was converted to the phosphoramidite rather than the PEG head group since previous attempts in this lab to prepare phosphoramidites from PEG alcohols had been unsuccessful. Coupling $\mathbf{2}$ and $\mathbf{7}$ via tetrazole proceeded smoothly followed by oxidation with MCPBA forming the orthogonally protected phosphate 8 . Catalytic hydrogenation liberated the PEG amine 9 which was used as a precursor for both FS-2 and FS-3. The PEG amino group was acylated via the N-hydroxysuccinimidyl ester (SE) of dabcyl forming 10. Treatment with TFA in $\mathrm{CH}_{2} \mathrm{Cl}_{2}$ removed the TBS and Boc groups and the resulting amine was acylated via BODIPY®-FL-SE yielding the fluorogenic substrate FS-2 (60\% from 9) The route to FS-3 followed the same sequences of reactions as FS-2. Treatment of 9 with FAM-SE gave 11 which was deprotected with TFA and labeled with dabcyl to yield FS-3 (51\% from 9).

The fluorogenic substrates were evaluated with recombinant ATX. FS-2 and FS-3 showed 2.8 and 10.7-fold increases in fluorescence respectively at $2.5 \mu \mathrm{M}$ when incubated with $75 \mathrm{nM}$ of ATX (Figure 2). An increase in fluorescence was not observed when either substrate was treated with an inactive ATX mutant (data not shown). $\mathrm{K}_{\mathrm{M}}$ and $\mathrm{V}_{\max }$ were determined for both substrates (Table 1) but a more detailed kinetic analysis and comparison with CPF4 and bisNPP will be described in a subsequent paper. ${ }^{17}$

Although FS-2 and FS-3 are effectively hydrolyzed by ATX (NPP2), neither would be expected to act as substrates for NPP1, NPP3, NPP4, or NPP5, which do not hydrolyze lysophospholipids. ${ }^{18,19}$ NPP6 has recently been shown to have lysoPLC activity, however it is selective for LPC over other lysophospholipids. Therefore, based on its headgroup specificity, it may not process FS-2 or FS-3. ${ }^{19}$ NPP7 posesses lysoPLC and sphingomyelinase activities but there is not enough evidence yet regarding headgroup specificity to preclude FS-2 or FS-3 acting as substrates. ${ }^{20}$

In conclusion, two dual-labeled ATX substrate analogs were synthesized featuring a fluor and a quencher on the $s n-1$ acyl chain and the ethanolamino headgroup. Because of the proximity of the two moieties, intramolecular energy transfer effectively quenches the fluorescence. Hydrolysis by recombinant ATX cleaved the phosphodiester bond resulting in a measurable increase in fluorescence. Since lysoPLD/ATX is an emerging potential drug target and biomarker, the substrates provide a simple, sensitive assay that could be applied to high throughput screening for diagnosis and drug discovery.

\section{Supplementary Material}

Refer to Web version on PubMed Central for supplementary material.

\section{Acknowledgment}

Work was supported by the National Cancer Institute (U01CA085133 to Echelon) and the Dutch Cancer Society (Netherlands Cancer Institute).

\section{References}

1. (a) Fang X, Gaudette D, Furui T, Mao M, Estrella V, Eder A, Pustilnik T, Sasagawa T, Lapushin R, Yu S, Jaffe RB, Wiener JR, Erikson JR, Mills GB. Ann. N.Y. Acad. Sci 2000;905:188. [PubMed: 10818454] (b) Luquain C, Sciorra VA, Morris A. Trends Biochem. Sci 2003;28:377. [PubMed: 12878005]

2. Hla T, Lee MJ, Ancellin N, Paik JH, Kluk MJ. Science 2001;294:1875. [PubMed: 11729304]

3. Mills GB, May C, McGill M, Roifman CM, Mellors A. Cancer Res 1988;48:1066. [PubMed: 3422589]

Org Lett. Author manuscript; available in PMC 2008 September 3. 
4. (a) Mills GB, Bast RC Jr. Srivastava S. J. Nat Cancer Inst 2001;93:1437. [PubMed: 11584052] (b) Mills GB, Eder A, Fang X, Hasegawa Y; Mao M, Lu Y, Tanyi J, Tabassam FH, Wiener J, Lapushin R; Yu S, Parrott JA, Compton T, Tribley W, Fishman D; Stack MS, Gaudette D, Jaffe R, Furui T, Aoki J, Erikson JR. Cancer treat. res 2002;107:259. [PubMed: 11775454] (c) Tanyi JL, Morris AJ, Wolf JK, Fang X, Hasegawa Y, LaPushin R, Auersberg N; Sigal Y, Newman RA, Felix EA, Atkinson EN, Mills GB. Cancer Res 2003;63:1073. [PubMed: 12615725]

5. Tokumura A, Harada K, Fukuzawa K, Tsukatani H. Biochim. Biophys.Acta 1986;875:31. [PubMed: 3632787]

6. (a) Tokumura A, Majima E, Kariyi Y, Tomingawa K, Kogure K, Yasuda K, Fukuzawa K. J. Biol. Chem 2002;277:39436. [PubMed: 12176993] (b) Moolenaar WH. J. Cell Biol 2002;158:197. [PubMed: 12135981] (c) Umezo-Goto M, Kishi Y, Taira A, Hama K, Dohmae N, Takio K, Yamori T, Mills GB, Inoue K, Aoki J, Arai H. J. Cell Biol 2002;158:227. [PubMed: 12119361] (d) Morris AJ, Engebrecht JA, Frohman MA. Trends Pharmacol. Sci 1996;17:182. [PubMed: 8669123]

7. (a) Goto M, Tanyi J, Lahad J, Liu S, Lapushin R, Hasegawa Y, Lu Y, Trost R, Bevers T, Jonasch E, Aldape K, Liu J, James RD, Ferguson CG, Xu Y, Prestwich GD, Mills GB. J. Cell. Biochem 2004;92:1115. [PubMed: 15258897] (b) Mills GB, Moolenaar WH. Nat. Rev. Cancer 2003;3:582. [PubMed: 12894246] (c) Feng L, Mills GB, Prestwich GD. Expert Oninions on Therapeutic Patents 2003;13:1619.

8. Tokumura A. Bpa Mol. Cell Biol. Lipids 2002;1582:18.

9. van Meeteren LA, Ruurs P, Christodoulou E, Goding JW, Takakusa H, Kikuchi K, Perrakis A, Nagano T, Moolenaar WH. J. Biol. Chem 2005;280:21155. [PubMed: 15769751]

10. Niewenhuizen W, van Leeuwen S, Gotz F, Egmond M. Chem. Phys. Lipids 2002;114:181. [PubMed: 11934399]

11. Sando S, Kool E. J. Am. Chem. Soc 2002;124:2096. [PubMed: 11878946] (b) Pankuch J, Coward J. Bioorg. Med. Chem. Lett 2001;11:1561. [PubMed: 11412981]

12. (a) Hendrickson HS, Kotz KJ, Hendrickson EK. Analyt. Biochem 1990;185:80. [PubMed: 2344049] (b) Feng L, Manabe K, Shope JC, Widmer S, DeWald DB, Prestwich GD. Chem. Biol 2002;9:795. [PubMed: 12144923] (c) Rose TM, Prestwich GD. ACS Chem. Biol 2006;1:83. [PubMed: 17163648]

13. Tyagi S, Kramer FR. Nat. Biotechnology 1996;14:303.

14. (a) Aoki J, Taira A, Takanezawa Y, Kishi Y, Hama K, Kishimoto T, Mizuno K, Saku K, Taguchi R, Arai H. J. Biol. Chem 2002;277:48737. [PubMed: 12354767] (b) Clair T, Aoki J, Koh E, Bandle RW, Nam SW, Ptaszynska MM, Mills GB. Cancer Res 2003;63:5446. [PubMed: 14500380]

15. Herbert N, Beck A, Lennox RB, Just G. J. Org. Chem 1992;57:1777.

16. Chen J, Feng L, Prestwich GD. J. Org. Chem 1998;63:6511.

17. van Meeteren, LA.; Ruurs, P.; Ferguson, CG.; Prestwich, GD.; Ovaa, H.; Moolenaar, WH. manuscript in preparation

18. Gijbers R, Aoki J, Arai H, Bollen M. FEBS Lett 2003;538:60. [PubMed: 12633853]

19. Sakagami H, Aoki J, Natori Y, Nishikawa K, Kakehi Y, Natori Y, Arai H. J. Biol. Chem 2005;280:23084. [PubMed: 15788404]

20. Duan R-D, Bergman T; Xu N, Wu J, Chen Y, Duan J, Nelander S, Palmberg C, Nilsson A. J. Biol. Chem 2003;278:38528. [PubMed: 12885774] 

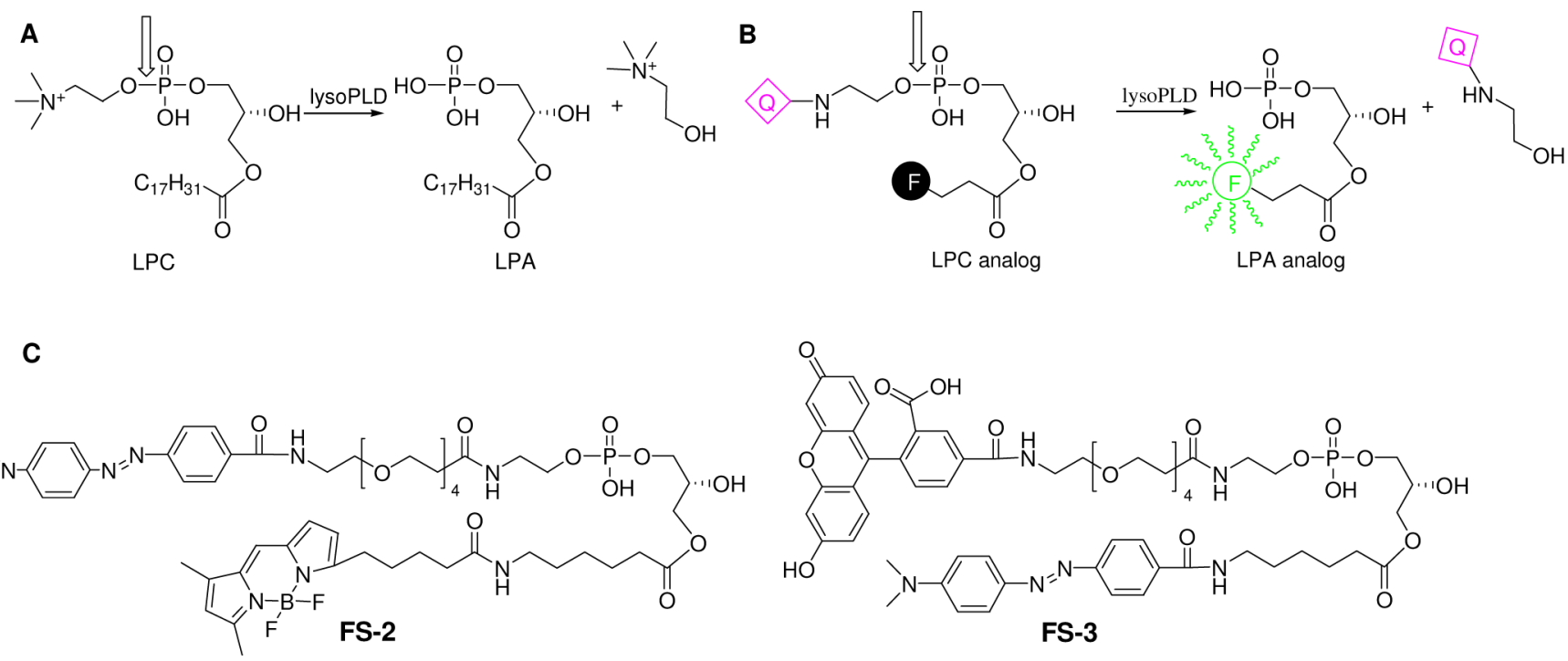

Figure 1.

A: Hydrolysis of oleoyl LPC by lysoPLD. B: Schematic of fluorescence-dequenching lysoPLD/ATX substrate. The fluor in the substrate is quenched through intramolecular energy transfer until hydrolyzed by the enzyme at which point the fluorescent product can be observed. C: Structures of fluorogenic substrates FS-2 and FS-3. 

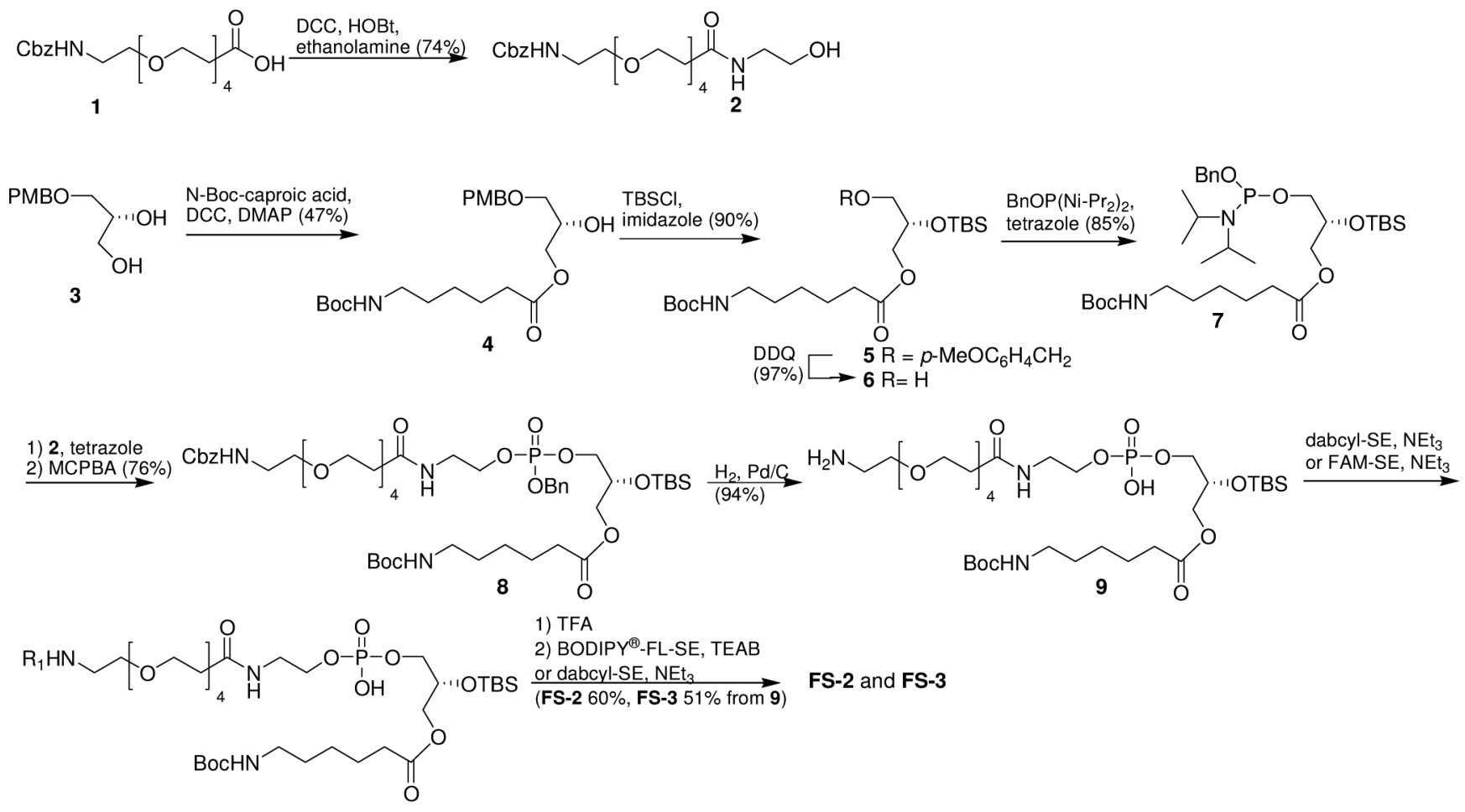

$10 R_{1}=$ Dabcyl

$11 R_{1}=$ Fluorescein

Scheme 1.

Synthesis of FS-2 and FS-3 


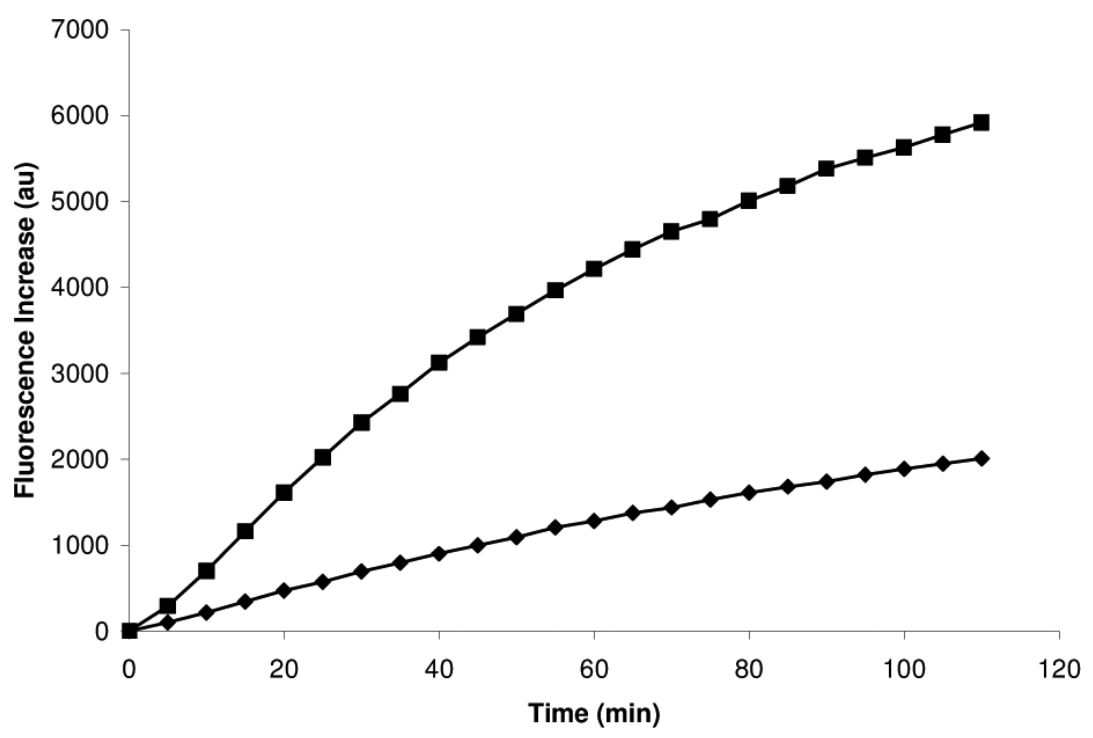

Figure 2.

Incubation of FS-2 ( ) and FS-3 ( $)$ with recombinant ATX results in a measurable increase in fluorescence (140 mM NaCl, $5 \mathrm{mM} \mathrm{KCl}, 1 \mathrm{mM} \mathrm{CaCl}_{2}, 1 \mathrm{mM} \mathrm{MgCl}$, $5 \mathrm{mM}$ Tris, pH 8.0, 1 $\mathrm{mg} / \mathrm{mL}$ fatty-acid free BSA, Absorption $485 \mathrm{~nm}$, Emission $520 \mathrm{~nm}, 37^{\circ} \mathrm{C}$ ) 
Table 1

Michaelis-Menten kinetics of hydrolysis of FS-2 and FS-3 by recombinant ATX ${ }^{a}$

\begin{tabular}{lcc}
\hline Substrate & $\mathbf{K}_{\mathbf{M}}(\boldsymbol{\mu M})$ & $\mathbf{V}_{\mathbf{m a x}}$ \\
\hline FS-2 & $3.1 \pm 0.6$ & $261 \pm 12.3$ \\
FS-3 & $6.3 \pm 0.2$ & $261 \pm 2.3$ \\
\hline$a_{\text {experimental details in Ref. 17. }}$ & & \\
$b_{\text {arbitrary fluorescence units/min. }}$ & &
\end{tabular}

